\title{
Temporomandibular joints disorders (TMDs) prevalence and their relation to anxiety in dental students [version 1; peer
}

\section{review: 1 approved with reservations]}

\author{
Lujain Homeida, Emtenan Felemban, Wed Kassar, Mazen Ameen, \\ Salwa Aldahlawi
}

Basic and Clinical Oral Sciences,, Umm-Al-Qura University, Makkah, 24382, Saudi Arabia

\begin{tabular}{l} 
V1 First published: 03 Mar 2022, 11:271 \\
https://doi.org/10.12688/f1000research.76178.1 \\
Latest published: 27 Apr 2022, 11:271 \\
https://doi.org/10.12688/f1000research.76178.2 \\
\hline
\end{tabular}

\section{Abstract}

Background: Temporomandibular joint disorders (TMDs) are very common disorders affecting the population and causing pain. Researchers have reported a high prevalence of TMDs among university students due to increased distress. The aims of this study were to determine the frequency of TMDs in Umm al-Qura University (UQU) dental students using the Diagnostic Criteria for Temporomandibular Disorders (DC/TMD), and to examine the relationship between anxiety, bruxism, and TMDs among those students.

Methods: The DC/TMD pain screener questionnaire was completed by dental students. Students who reported TMD pain or had at least one positive TMD symptom were invited to the dental clinic for a full TMJ evaluation. History of bruxism was documented and an ultra-brief tool for detecting anxiety and depression (Patient Health Questionnaire-4 PHQ) was completed by all students.

Results: A total of 240 students responded to the TMD pain screener in which 119 reported at least one TMJ symptom. Only 93 dental students presented to clinical examination in which $64.5 \%(n=60)$ of them had temporomandibular joint disorders. Disc displacement with reduction and local myalgia ( $38.7 \% \& 32.25 \%$, respectively) were the most frequent diagnosis. A total of $29 \%(n=27)$ of students had more than one diagnosis. Overall, 41 participants (44.09\%) reported a positive response to the anxiety scale and $(n=38) 40 \%$ of participants reported parafunctional habits. Both the history of bruxism and anxiety were significantly related to TMDs ( $\mathrm{P}=0.0002)$ and also significantly higher in women of higher academic years $(P \leq 0.01)$. Conclusions: This study found a high prevalence of TMDs among UQU dental students. Disc displacement with reduction was the most prevalent disorder. Bruxism and anxiety were associated with painful TMDs.

\section{Open Peer Review \\ Approval Status \\ 1 \\ version 2 \\ (revision) \\ 27 Apr 2022 \\ version 1 \\ 03 Mar 2022

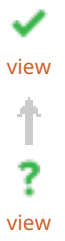 \\ 1. Arwa Farag (iD), Tufts School of Dental \\ Medicine, Boston, USA}

Any reports and responses or comments on the article can be found at the end of the article. 
Keywords

TMD, DENTAL, STUDENTS, PAIN, STRESS , PARAFUNCTIONAL HABITS

Corresponding author: Lujain Homeida (lahomeida@uqu.edu.sa)

Author roles: Homeida L: Conceptualization, Data Curation, Investigation, Methodology, Project Administration, Resources, Supervision, Visualization, Writing - Original Draft Preparation, Writing - Review \& Editing; Felemban E: Investigation, Methodology, Visualization, Writing - Original Draft Preparation; Kassar W: Investigation, Methodology, Visualization, Writing - Original Draft Preparation; Ameen M: Formal Analysis, Investigation, Methodology, Software, Visualization, Writing - Original Draft Preparation; Aldahlawi S: Conceptualization, Data Curation, Formal Analysis, Investigation, Methodology, Validation, Visualization, Writing - Original Draft Preparation, Writing - Review \& Editing

Competing interests: No competing interests were disclosed.

Grant information: The author(s) declared that no grants were involved in supporting this work.

Copyright: (c) 2022 Homeida L et al. This is an open access article distributed under the terms of the Creative Commons Attribution License, which permits unrestricted use, distribution, and reproduction in any medium, provided the original work is properly cited.

How to cite this article: Homeida L, Felemban E, Kassar W et al. Temporomandibular joints disorders (TMDs) prevalence and their relation to anxiety in dental students [version 1; peer review: 1 approved with reservations] F1000Research 2022, 11:271

https://doi.org/10.12688/f1000research.76178.1

First published: 03 Mar 2022, 11:271 https://doi.org/10.12688/f1000research.76178.1 


\section{Introduction}

Temporomandibular joint disorders (TMDs) are a very common group of musculoskeletal disorders affecting the temporomandibular joint (TMJ) and the face causing pain. They are considered a significant public health burden in approximately $5 \%$ to $12 \%$ of the general population (National Institute of Dental and Craniofacial Research 2018, July). Painful TMD has a direct impact on the person's quality of life and daily activity (Schiffman, Ohrbach et al. 2014). The TMD has a multifactorial pathogenesis in which it involves physiological and/or psychological factors like emotional distresses. Chronic parafunctional habits can cause repetitive trauma to the masticatory system, which may result in painful TMD episodes (Schiffman, Ohrbach et al. 2014). Parafunctional habits including but not limited to bruxing and clenching are known to have a critical role in aggravation and progression of TMD (Chisnoiu, Picos et al. 2015). Furthermore, psychosocial distress is also considered an important comorbidity contributing to TMD (Schiffman, Ohrbach et al. 2014). Some individuals, when exposed to stressful situations, tend to activate the stomatognathic system by clenching or grinding their teeth and increasing masticatory muscle contraction in order to relieve their stress. This increased masseter activation during stress and decrease in a relaxing situation was highly associated with the presence of TMD in individuals under more stress (Calixtre, Gruninger et al. 2014).

Many studies have looked into the psychological stress among university students and its impact on student's academic achievement and well-being. High prevalence of mental issues between university students was reported (Adlaf, Gliksman et al. 2001). Stallman et al evaluated mental stress among Australian universities students and found a high prevalence of mental health problems $(19.2 \%)$ and subsyndromal symptoms $(67.4 \%)$ which were significantly higher than those of the general population (Stallman 2010). This supports that university student population live under more stress than the general population. Thus, the prevalence of TMDs is relatively high among university students of different specialties.

Binoleil et al, assessed the prevalence of headaches and painful TMDs and examined the relationship between TMDs, headaches, and depression rates among dental and medical students. They reported higher depression scores in patients with painful TMD compared to patients without TMD (Benoliel, Sela et al. 2011). Furthermore, the relationship between stress level and painful TMD in students of health science was supported in few more studies locally (Alkhudhairy, $\mathrm{Al}$ Ramel et al. 2018) and internationally where stress played an important role in TMD progression (Monteiro, Zuim et al. 2011, Wieckiewicz, Grychowska et al. 2014).

The Research Diagnostic Criteria for Temporomandibular Disorders (RDC/TMD) was first proposed in 1992 and has been used widely as diagnostic protocol for TMD research (Dworkin and LeResche 1992). However, more research was done over the years to improve its validity and clinical utility. In 2014, an evidence-based new Diagnostic Criteria for Temporomandibular Disorders (DC/TMD) was published and was considered a valid and reliable screening tool for use in clinical and research settings and included important modifications to the original RDC/TMD (Schiffman, Ohrbach et al. 2014). An acceptable sensitivity and specificity for a definitive diagnosis are considered as sensitivity $\geq 70 \%$ and specificity $\geq 95 \%$. DC/TMD has diagnostic algorithms used to diagnose the most common pain-related TMD and most common intra-articular disorders (Schiffman, Ohrbach et al. 2014). The Axis I diagnostic algorithm consists of two parts; a self-report instrument where it is used for pain screening. The second part is used for TMJ clinical examination. The DC/TMD Axis II protocol included instruments to evaluate pain behavior, psychological status, and psychosocial functioning (Schiffman, Ohrbach et al. 2014).

To the best of our knowledge, the prevalence of TMDs among Umm al-Qura University (UQU) dental students has not been evaluated. In this study, we aimed to determine the prevalence of TMDs in UQU dental students using Diagnostic Criteria for Temporomandibular Disorders (DC/TMD). Also, to examine the relation between anxiety, self-reported bruxism and TMDs among UQU dental students.

\section{Methods}

This cross-sectional study was approved from Umm Al-Qura University (UQU), College of Dentistry Institutional Review Board (IRB) \# (98-18). This study took place at collage of Dental Medicine Umm al Qura University. Data were collected between July 2019 and December 2019.

\section{Screening dental students for TMDs}

The UQU dental collage program starts at $2^{\text {nd }}$ level and it is involves 5 academic years followed by internship year. All UQU dental students (year 2 - internship year) were included in this study and were invited by email to fill The Research Diagnostic Criteria (RDC) three-items pain screener on TMD symptoms (Schiffman, Ohrbach et al. 2014). Non-dental students from UQU and dental student from other universities were excluded. All participants have given their consent to participate in the study. Demographic data were collected including age, gender, marital status and year of study. 
In addition, history of TMD diagnosis and history of parafunctional habits (bruxism), and the use of chronic medication was included. The response to each of the three questions was documented.

\section{TMJ clinical examination and diagnosis}

The respondents who reported TMD pain or had at least one positive answer to one of the 3-items questionnaire were invited to have a full TMJ clinical examination in the specialty clinic at UQU teaching hospital. The TMJ clinical examination included detailed assessment of the TMJ position and structure, range of motion measurements, and palpation of muscle of mastication following DC/TMD protocol. The clinical examination provided to all students was performed by one oral medicine/TMD specialist. Written informed consent was obtained from all participants prior to clinical examination.

The DC/TMD diagnostic criteria algorithms were followed to reach a TMD diagnosis. This included pain-related temporomandibular disorders (local myalgia, myofascial pain, myofascial pain with referral, arthralgia, and headache attributed to TMD) and intra-articular disorders (disc displacement with reduction, disc displacement with reduction with intermittent locking, disc displacement without reduction with limited opening, disc displacement without reduction without limited opening). History of bruxism was obtained and those who had painful TMD were referred to an oral medicine specialist clinic for further treatment.

\section{Anxiety and depression scale}

During the clinical examination, a valid and ultra-brief tool for detecting anxiety and depression (Patient Health Questionnaire-4 PHQ) was completed by all participants (Kroenke, Spitzer et al. 2009). This four-items questionnaire (PHQ-4) consisted of two core anxiety and two core depression items. The total score of this scale ranges from 0-12 and categorized as normal (0-2), mild (3-5), moderate (6-8), and severe (9-12). This instrument is not diagnostic, however, is indicator for further assessment of possible clinical disorder warranting treatment.

\section{Data analysis}

The data analysis was performed using Statistical Package for the Social Sciences version 22 (SPSS Inc., Chicago, IL, USA, RRID:SCR_019096). Student T-test and chi-square analysis were used to relate the existence of TMD problem to age, gender, academic year, history of bruxism and anxiety level. Also, to compare the anxiety scores among male and female groups. Statistical significance was set at $P \leq 0.05$.

\section{Results}

A total of 304 electronic questionnaires were sent via email to all dental students at Umm al-Qura university who were between $2^{\text {nd }}$ year to the internship with a total of 6 academic years. A total of 240 questionnaires were completed and returned with a compliance rate of $78.9 \%$ (Homeida 2022). The demographics of respondents from the pain screening questionnaire can be found in Table 1.

Table 1. Demographic data of participants who responded positive to the pain screener and who presented for the temporomandibular joint (TMJ) clinical examination.

\begin{tabular}{|l|l|l|}
\hline & Respondents to pain screener $(\mathbf{n = 2 4 0})$ & Participants in TMJ clinical examination (n=93) \\
\hline Age & $22.38 \pm 1.2$ year & $22.3 \pm 1.25$ year \\
\hline Gender & $131(54 \%)$ & $45(48.4 \%)$ \\
\hline Male & $109(46 \%)$ & $48(51.6 \%)$ \\
\hline Female & & \\
\hline Academic Year & $11(4.5 \%)$ & $3(3.2 \%)$ \\
\hline $2^{\text {nd }}$ year & $46(19.1 \%)$ & $12(12.9 \%)$ \\
\hline $3^{\text {rd }}$ year & $42(17.5 \%)$ & $14(15.1 \%)$ \\
\hline $4^{\text {th }}$ year & $56(23.3 \%)$ & $25(26.9 \%)$ \\
\hline $5^{\text {th }}$ year & $55(22.9 \%)$ & $27(28 \%)$ \\
\hline $6^{\text {th }}$ year & $30(12.5 \%)$ & $12(14 \%)$ \\
\hline Internship year & & \\
\hline
\end{tabular}


Temporomandibular joint disorder pain screener results

Out of the 240 responders, $49.5 \%(n=119)$ reported either TMD pain or other TMD symptoms in the past 30 days. And $20.4 \%(\mathrm{n}=49)$ reported TMJ pain that comes and goes. The majority of students $30 \%(\mathrm{n}=72)$ reported jaw habits with $25 \%$ $(n=60)$ had pain on opening, 16\% $(n=40)$ reported pain on chewing hard or tough food and $14 \%(n=35)$ had pain with jaw activities such as talking and yawning (Table 2).

Prevalence of TMDs among dental students

All the responders who reported TMD pain or symptoms $(n=119)$ were invited for a TMJ examination. A total of $93(78 \%)$ subjects presented for clinical assessment. The demographics of the subjects received the clinical examination are presented in Table 1. During TMJ clinical examination, more than half of the subjects $64.5 \%(\mathrm{n}=60)$ had temporomandibular disorders (TMDs), while only 35.4\% ( $n=33$ ) students had normal TMJ findings at the time of the examination.

Disc displacement with reduction was the most frequent diagnosis $38.7 \%(\mathrm{n}=36)$ followed by local myalgia $32.25 \%$ $(\mathrm{n}=30)$ and arthralgia $16.1 \%(\mathrm{n}=15)$ (Figure 1). Interestingly, 29\% ( $\mathrm{n}=27)$ students had more than one diagnosis and coexistence of disc displacement with reduction and local myalgia was found to be the most frequent combination in $19.3 \%(\mathrm{n}=18)$ students (Table 3$)$. Overall, the diagnosis of TMD was significantly higher in the female students compared to the male students $(\mathrm{P} \leq 0.022)$. Both, pain-related disorders and intra-articular disorders were significantly higher in females with $(\mathrm{P}=0.027)$ and $(\mathrm{P}=0.024)$, respectively. Also, disc displacement with reduction showed a significant increase with the higher academic year $(\mathrm{P} \leq 0.01)$.

\section{Anxiety and depression scale and history of parafunctional habits}

In total, 41 participants (44.09\%) reported a positive response to the anxiety and depression scale. In which, $48.7 \%(n=20)$ had a mild score and $51 \%(\mathrm{n}=21)$ had moderate to severe anxiety score (Table 3$)$. Of the 41 subjects with a positive response to PHQ-4, 31 (73\%) had been diagnosed with a painful TMDs. Moderate to severe anxiety was significantly associated with TMDs $(\mathrm{P}=0.006)$.

Table 2. Results of temporomandibular joint disorder pain screener $(n=240)$.

\begin{tabular}{|l|l|}
\hline & $\begin{array}{l}\text { Frequency } \\
\text { n (\%) }\end{array}$ \\
\hline In the last 30 days, how long did any pain last in your jaw or temple area on either side? & \\
\hline No pain & $189(78.7)$ \\
\hline Pain comes and goes & $49(20.4)$ \\
\hline Pain is always present & $2(0.8)$ \\
\hline In the last 30 days, have you had pain or stiffness in your jaw on awakening? & $45(18.7)$ \\
\hline Yes & 195 (81.2) \\
\hline No & \\
\hline $\begin{array}{l}\text { last } 30 \text { days, did the following activities change any pain (that is, make it better or it worse) in } \\
\text { your jaw or temple area on either side? Chewing hard or tough food }\end{array}$ & $40(16)$ \\
\hline Yes & $200(83)$ \\
\hline No & \\
\hline Opening your mouth or moving your jaw forward or to the side & $60(25)$ \\
\hline Yes & $180(75)$ \\
\hline No & \\
\hline Jaw habits such as holding teeth together, clenching, grinding, or chewing gum & 205 (86) \\
\hline Yes & $72(30)$ \\
\hline No & $168(70)$ \\
\hline Other jaw activities such as talking, kissing, or yawning & \\
\hline Yes & $35(14)$ \\
\hline
\end{tabular}




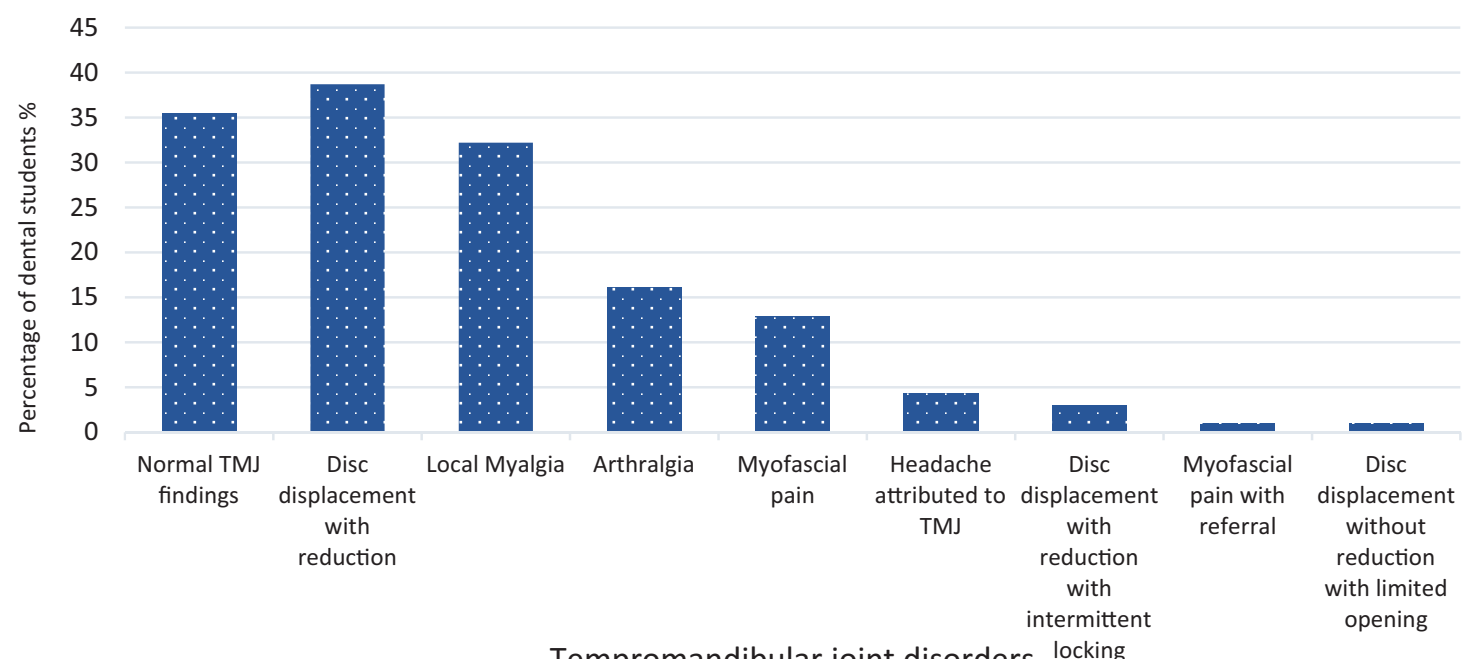

Figure 1. Percentage of dental students presenting with DC/TMD Diagnosis. DC/TMD: Diagnostic Criteria for Temporomandibular Disorders.

Table 3. Gender based distribution of TMDs, Anxiety scale and history of bruxism.

\begin{tabular}{|l|l|l|l|}
\hline & Female N (\%) & Male N (\%) & Total N (\%) \\
\hline Total number of participants & $45(48.3)$ & $48(51.6)$ & $93(100)$ \\
\hline Bruxism & $28(30)$ & $10(10.7)$ & $38(40.8)$ \\
\hline TMDs & & & \\
\hline Normal TMJ findings & $12(12.9)$ & $21(22.5)$ & $33(35.4)$ \\
\hline Disc displacement with reduction & $22(23.6)$ & $14(15)$ & $38.7(36)$ \\
\hline Local myalgia & $16(17)$ & $14(15)$ & $32.2(30)$ \\
\hline Myofascial pain & $11(11.8)$ & $1(1)$ & $12.9(12)$ \\
\hline Arthralgia & $5(5.3)$ & $10(10.7)$ & $16.1(15)$ \\
\hline Headache attributed to TMD & $4(4)$ & 0 & $4.3(4)$ \\
\hline Disc displacement with reduction with intermittent locking & $3(3)$ & 0 & $3(3)$ \\
\hline Myofascial pain with referral & $1(1)$ & 0 & $1(1)$ \\
\hline Disc displacement without reduction with limited opening & $1(1)$ & 0 & $1(1)$ \\
\hline PHQ-4 & & & $20(21.5)$ \\
\hline Mild & $16(17)$ & $1(4)$ & $21(22.5)$ \\
\hline Moderate to severe & $20(21.5)$ & $1(1)$ & \\
\hline
\end{tabular}

TMD: Temporomandibular disorders. PHQ-4: Patient Health Questionnaire-4.

Overall, $40 \%$ of the participants $(\mathrm{n}=38)$ reported a parafunctional habit. Out of $38(71 \%)$ with a history of bruxism, $27 \mathrm{had}$ TMDs. Self-reported history of bruxism was significantly associated with TMDs in all students $(\mathrm{P} \leq 0.01)$.

Both the history of bruxism and the level of anxiety were significantly related $(\mathrm{P}=0.0002)$ and also significantly higher in females than males $(\mathrm{P} \leq 0.01)$. Besides, the anxiety level and history of bruxism significantly increased with higher academic years $(\mathrm{P} \leq 0.05)$. Those high scores of anxieties and bruxism were reversed in the internship year (Figure 2).

\section{Discussion}

The present study found that half of UQU dental students reported at least one TMD symptom. Moreover, the clinical examination found that $64 \%$ were diagnosed with at least one TMJ disorder and about $30 \%$ (one- third) had multiple diagnoses. Bruxism and high anxiety levels were related to TMDs in this student population. 


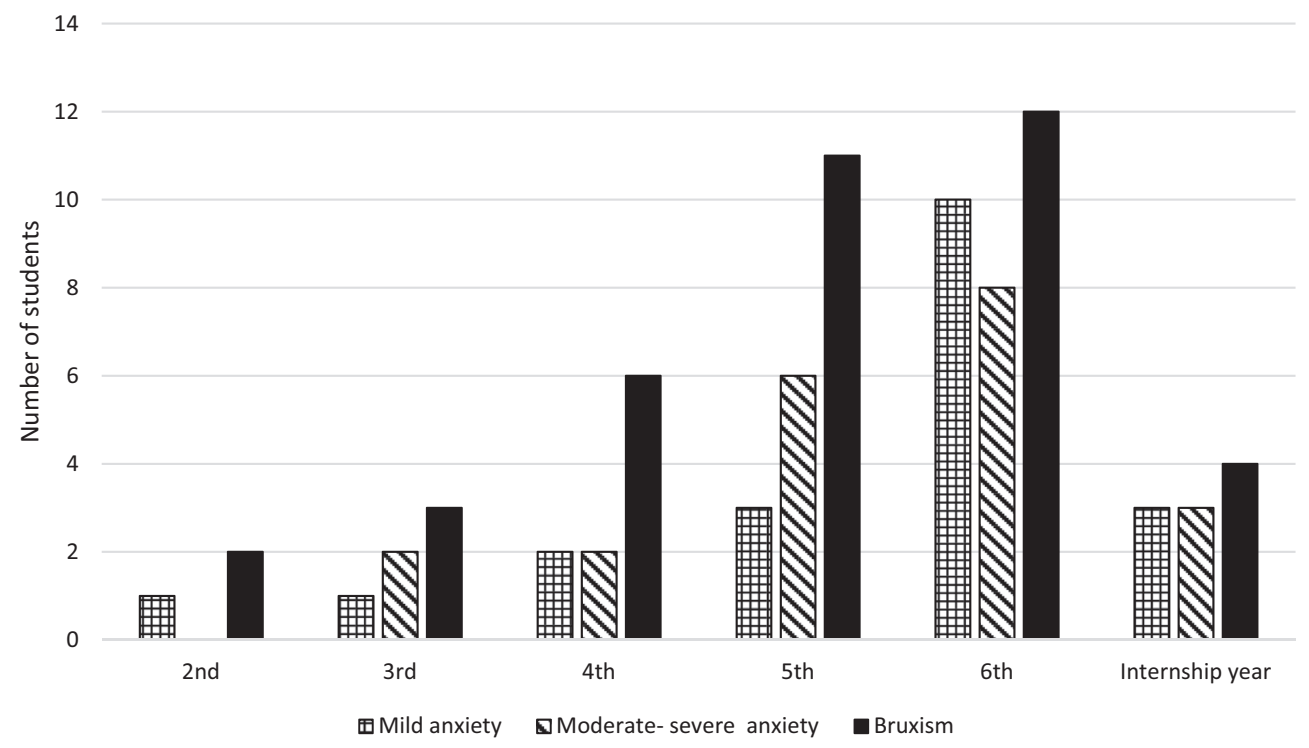

Figure 2. History of bruxism and anxiety levels significantly increased with higher academic years and declined in internship year.

Evidence suggests that TMD is a common complain among students. The prevalence of TMD reported by this study is higher than what has been reported by other studies in Saudi universities which ranged between 25-39\% (Alkhudhairy, Al Ramel et al. 2018, Srivastava, Shrivastava et al. 2021). Studies that addressed general university Saudi students also reported TMD prevalence of 20 to 50\% (Zulqarnain, Khan et al. 1998, Habib, Al Rifaiy et al. 2015, Zwiri and Al-Omiri 2016, Srivastava, Shrivastava et al. 2021). All the above-mentioned studies with the exception of Srivastava et al. relied on self-administered questioners to identify subjects with TMDs and did not include TMJ clinical examination to confirm the diagnosis as the present study which may explain the difference in prevalence. When RDC/TMD algorithm was used to estimate the prevalence of TMD, 30 to $36 \%$ of dental students were found to have TMD (Fernandes Azevedo, CamaraSouza et al. 2018, Lövgren, Österlund et al. 2018). The present study used RDC/TMD pain screener to identify the subject with possible TMJ symptoms first, then, only those with positive responses to the pain screener were examined clinically for TMD diagnosis and that may explain the higher prevalence of TMDs.

Disc displacement with reduction was the most prevalent TMD disorder followed by myalgia. This finding concurs with a systematic review in which disc displacement of TMJ was highly prevalent TMD in the general population with prevalence ranging from 18 to 35\% (Naeije, Te Veldhuis et al. 2013). Also, the finding of the increasing prevalence of disc displacement with age in this study is in alignment with other studies were disc displacement with reduction develops during childhood and adolescence and it's prevalence levels off towards adulthood (Marpaung, van Selms et al. 2019, Sankuratri, Verma et al. 2021). Although myalgia was the reported as the commonest diagnosed condition in some studies (Srivastava, Shrivastava et al. 2021), it was the second most prevalence condition in this study. On the other hand, females had a higher prevalence of TMDs compared to males. This findings was in alignment with other studies (Bagis, Ayaz et al. 2012, Naeije, Te Veldhuis et al. 2013, Wieckiewicz, Grychowska et al. 2014, de Melo Junior, Aroucha et al. 2019, Xie, Lin et al. 2019, Sankuratri, Verma et al. 2021, Srivastava, Shrivastava et al. 2021). Interestingly, 30\% of the subjects had more than one TMDs diagnosis. Similar finding were reported by Azevedo 2018 et al (Fernandes Azevedo, Camara-Souza et al. 2018) which highlights the importance of diagnosis and early management of TMDs.

Previous cross-sectional studies reported a significant increase in anxiety and depression scores among medical and dental students in different Saudi universities (Inam 2007, Aboalshamat, Hou et al. 2015, Basudan, Binanzan et al. 2017). In this study, $44 \%$ of the students with TMD symptoms reported a positive response to the PHQ-4 with half of them classified as having moderate to severe anxiety. Female dental students had a higher PHQ-4 mean score than male students which was in agreement with similar studies done on Saudi dental students (Inam 2007, Al-Saleh, Al-Madi et al. 2010, Benoliel, Sela et al. 2011, Al-Sowygh 2013). Overall, the rate of anxiety in women has been reported to be higher than men (Kessler, Sonnega et al. 1995, Steel, Marnane et al. 2014, Xie, Lin et al. 2019). This could be explained by the slower processing in neurotransmitter serotonin which has a critical role in anxiety and depression. Besides, women are more sensitive to specific hormone such as corticotropin-releasing factor which has an important role in stress response (Bangasser, Curtis et al. 2010). 
The majority of those students who showed moderate to severe levels of anxiety and depression were diagnosed with painful TMDs on clinical examination and therefore, anxiety was found to be related to TMDs. Other studies have conflicting results. stress and anxiety were positively associated with TMD in university students in general and dental students in particular (Ton, Mota et al. 2020, Jaiswal and Deshpande 2021). While Azevedo et al found no association between anxiety and TMD (Fernandes Azevedo, Camara-Souza et al. 2018). Anxiety and stress in dental students can be caused by many external factors like exams, clinical requirements and academic assignments. This study was conducted during the academic year which could contribute to the higher prevalence of anxiety and TMDs.

In general, oral parafunctional habits are known as a major contributor to TMDs and play an important role in its progression (Chisnoiu, Picos et al. 2015). In the present study, self-reported bruxism was significantly associated with TMDs. This finding concurs similar findings in Swedish dental students in which participants with TMD reported significantly higher oral parafunctional habits (Lövgren, Österlund et al. 2018). Moreover, the results of this study are in accordance with Jaiswal et al, where they reported significant relationship between TMDs and parafunctional habits in Indian dental students (Jaiswal and Deshpande 2021).

History of bruxism and anxiety levels were found to be higher among the senior dental students at UQU. Similar findings were reported by other studies in which a statistical significant relationship between anxiety and the para-functional habit was revealed (Paterson, Lamb et al. 1995, Ahlberg, Lobbezoo et al. 2013). Most individuals who have anxiety disorders tend to relieve their stress by clenching and/or grinding their teeth and contracting masticatory muscle which leads to activation of the stomatognathic system (Calixtre, Gruninger et al. 2014). This increase in stress levels among final-years students can be due to more participants from those two academic years. However, it can be also explained by the higher clinical demands and more workload during these final clinical years. Declining of both bruxism and anxiety parameters was noted in participants from the internship year where there is a significant decrease in academic load and clinical requirements. Similar findings were reported by Ahuja (Ahuja, Ranjan et al. 2018).

\section{Limitation of the study}

This is a cross-sectional study in which only association between variables is detected. Longitudinal studies are needed to prove causation. The absence of a control group for anxiety screening was regarded as a limitation for this study, as no clinical examination nor depression score was done for the participants who denied TMD pain or symptoms. Also, a comparison of TMDs prevalence with age-matched general population (non-dental students) was not considered in this study and it is recommended for future research projects.

\section{Conclusions}

TMDs is highly prevalent among dental students. Disc displacement with reduction was the most predominant one. Greater prevalence was observed among females and higher academic years. Bruxism and anxiety were associated with painful TMDs.

\section{Data availability}

Underlying data

Dryad: Temporomandibular Joints Disorders TMDs Prevalence and Its Relation to Anxiety in Dental Students. https:// doi.org/10.5061/dryad.kkwh70s62 (Homeida 2022).

This project contains the following underlying data:

- Pain screener results for 240 participants.xlsx

- TMD diagnosis results of 93 participants.xlsx

Data are available under the terms of the Creative Commons Zero "No rights reserved" data waiver (CC0 1.0 Public domain dedication). 
Aboalshamat K, Hou XY, Strodl E: Psychological well-being status among medical and dental students in Makkah, Saudi Arabia: a crosssectional study. Med. Teach. 2015; 37(Suppl 1): S75-S81.

PubMed Abstract | Publisher Full Text

Adlaf EM, Gliksman L, Demers A, et al.: The prevalence of elevated psychological distress among Canadian undergraduates: findings from the 1998 Canadian Campus Survey. J. Am. Coll. Heal. 2001; 50(2): 67-72.

PubMed Abstract | Publisher Full Text

Ahlberg J, Lobbezoo F, Ahlberg K, et al.: Self-reported bruxism mirrors anxiety and stress in adults. Med. Oral Patol. Oral Cir. Bucal. 2013; 18(1): e7-e11.

Ahuja V, Ranjan V, Passi D, et al.: Study of stress-induced temporomandibular disorders among dental students: An institutional study. Natl. J. Maxillofac. Surg. 2018; 9(2): 147-154. PubMed Abstract | Publisher Full Text

Al-Saleh SA, Al-Madi EM, Al-Angari NS, et al.: Survey of perceived stressinducing problems among dental students, Saudi Arabia. Saudi. Dent. J. 2010; 22(2): 83-88.

PubMed Abstract | Publisher Full Text

Al-Sowygh ZH: Academic distress, perceived stress and coping strategies among dental students in Saudi Arabia. Saudi. Dent. J. 2013; 25(3): 97-105.

PubMed Abstract | Publisher Full Text

Alkhudhairy MW, Al Ramel F, Al Jader G, et al.: A Self-Reported Association between Temporomandibular Joint Disorders, Headaches, and Stress. J. Int. Soc. Prev. Community Dent. 2018; 8(4): 371-380.

PubMed Abstract | Publisher Full Text

Bagis B, Ayaz EA, Turgut S, et al.: Gender difference in prevalence of signs and symptoms of temporomandibular joint disorders: a retrospective study on $\mathbf{2 4 3}$ consecutive patients. Int. J. Med. Sci. 2012 9(7): 539-544.

PubMed Abstract | Publisher Full Text

Bangasser DA, Curtis A, Reyes BA, et al.: Sex differences in corticotropinreleasing factor receptor signaling and trafficking: potential role in female vulnerability to stress-related psychopathology. Mol. Psychiatry 2010; 15(9): 877. 896-904.

Publisher Full Text

Basudan S, Binanzan N, Alhassan A: Depression, anxiety and stress in dental students. Int. J. Med. Educ. 2017; 8: 179-186.

PubMed Abstract | Publisher Full Text

Benoliel R, Sela G, Teich S, et al.: Painful temporomandibular disorders and headaches in $\mathbf{3 5 9}$ dental and medical students. Quintessence Int. 2011; 42(1): 73-78.

PubMed Abstract

Calixtre LB, Gruninger BL, Chaves TC, et al.: Is there an association between anxiety/depression and temporomandibular disorders in college students? J. Appl. Oral Sci. 2014; 22(1): 15-21.

PubMed Abstract | Publisher Full Text

Chisnoiu AM, Picos AM, Popa S, et al.: Factors involved in the etiology of temporomandibular disorders - a literature review. Clujul. Med. 2015; 88(4): 473-478

PubMed Abstract | Publisher Full Text

de Melo Junior PC, Aroucha J, Arnaud M, et al.: Prevalence of TMD and level of chronic pain in a group of Brazilian adolescents. PLOS One. 2019; 14(2): e0205874.

PubMed Abstract | Publisher Full Text

Dworkin SF, LeResche L: Research diagnostic criteria for temporomandibular disorders: review, criteria, examination and specifications, critique. J. Craniomandib. Disord. 1992; 6(4): 301-355. PubMed Abstract

Fernandes Azevedo AB, Camara-Souza MB, Dantas IS, et al.: Relationship between anxiety and temporomandibular disorders in denta students. Cranio. 2018; 36(5): 300-303.

PubMed Abstract | Publisher Full Text

Habib SR, Al Rifaiy MQ, Awan KH, et al.: Prevalence and severity of temporomandibular disorders among university students in Riyadh. Saudi. Dent. J. 2015; 27(3): 125-130.

PubMed Abstract | Publisher Full Text

Homeida L: Temporomandibular joints disorders TMDs prevalence and its relation to anxiety in dental students. Dryad, Dataset 2022

Publisher Full Text

Inam SB: Anxiety and Depression among Students of a Medical College in Saudi Arabia. Int. J. Health Sci. (Qassim) 2007; 1(2): 295-300. PubMed Abstract
Jaiswal E, Deshpande S: Temporomandibular Disorders in Dental Students ofIndia: Prevalence, Severity and Associated Factors. Clin. Dent. 2021; XV(4): 12-17.

Kessler RC, Sonnega A, Bromet E, et al.: Posttraumatic stress disorder in the National Comorbidity Survey. Arch. Gen. Psychiatry 1995; 52(12): 1048-1060.

Publisher Full Text

Kroenke K, Spitzer RL, Williams JB, et al.: An ultra-brief screening scale for anxiety and depression: the PHQ-4. Psychosomatics 2009; 50(6):613-621. PubMed Abstract | Publisher Full Text

Lövgren A, Österlund C, Ilgunas A, et al.: A high prevalence of TMD is related to somatic awareness and pain intensity among healthy dental students. Acta Odontol. Scand. 2018; 76(6): 387-393.

PubMed Abstract | Publisher Full Text

Marpaung C, van Selms MKA, Lobbezoo F: Temporomandibular joint anterior disc displacement with reduction in a young population: Prevalence and risk indicators. Int. J. Paediatr. Dent. 2019; 29(1): 66-73. PubMed Abstract | Publisher Full Text

Monteiro DR, Zuim PR, Pesqueira AA, et al.: Relationship between anxiety and chronic orofacial pain of temporomandibular disorder in a group of university students. J. Prosthodont. Res. 2011; 55(3): 154-158. PubMed Abstract | Publisher Full Text

Naeije M, Te Veldhuis AH, Te Veldhuis EC, et al.: Disc displacement within the human temporomandibular joint: a systematic review of a 'noisy annoyance'. J. Oral Rehabil. 2013; 40(2): 139-158.

PubMed Abstract | Publisher Full Text

National Institute of Dental and Craniofacial Research: Facial Pain. 2018, July, July 2018. Retrieved 28. March, 2020.

Reference Source

Paterson AJ, Lamb AB, Clifford TJ, et al.: Burning mouth syndrome: the relationship between the HAD scale and parafunctional habits. J. Oral Pathol. Med. 1995; 24(7): 289-292.

PubMed Abstract | Publisher Full Text

Sankuratri B, Verma RK, Iqbal A, et al.: Assessment of Incidence of TMJ Disorders in Dental Graduates Competing for Post Graduation Exam: Original Research. Ann. Rom. Soc. Cell Biol. 2021; 25(6): 10837-10842.

Schiffman E, Ohrbach R, Truelove E, et al.: Diagnostic Criteria for Temporomandibular Disorders (DC/TMD) for Clinical and Research Applications: recommendations of the International RDC/TMD Consortium Network* and Orofacial Pain Special Interest Groupdagger. J. Oral Facial Pain Headache. 2014; 28(1): 6-27.

PubMed Abstract|Publisher Full Tex

Srivastava KC, Shrivastava D, Khan ZA, et al.: Evaluation of temporomandibular disorders among dental students of Saudi Arabia using Diagnostic Criteria for Temporomandibular Disorders (DC/TMD): a cross-sectional study. BMC Oral Health. 2021; 21(1): 211.

PubMed Abstract | Publisher Full Text

Stallman H: Psychological distress in university students: A comparison with general population data. Aust. Psychol. 2010; 45(4): 249-257.

Publisher Full Text

Steel Z, Marnane C, Iranpour C, et al.: The global prevalence of common mental disorders: a systematic review and meta-analysis 1980-2013. Int. J. Epidemiol. 2014; 43(2): 476-493.

PubMed Abstract | Publisher Full Text

Ton LAB, Mota IG, Martins APVB, et al.: Prevalence of temporomandibular disorder and its association with stress and anxiety among university students. Brazilian Dent. Sci. 2020; 23(1). Publisher Full Text

Wieckiewicz M, Grychowska N, Wojciechowski K, et al.: Prevalence and correlation between TMD based on RDC/TMD diagnoses, oral parafunctions and psychoemotional stress in Polish university students. Biomed. Res. Int. 2014; 2014: 472346.

Xie $\mathrm{C}$, Lin $\mathrm{M}$, Yang $\mathrm{H}$, et al.: Prevalence of temporomandibular disorders and its clinical signs in Chinese students, 1979-2017: A systematic review and meta-analysis. Oral Dis. 2019; 25(7): 1697-1706.

PubMed Abstract | Publisher Full Text

Zulqarnain BJ, Khan N, Khattab S: Self-reported symptoms of temporomandibular dysfunction in a female university student population in Saudi Arabia. J. Oral Rehabil. 1998; 25(12): 946-953. PubMed Abstract | Publisher Full Text

Zwiri AM, Al-Omiri MK: Prevalence of temporomandibular joint disorder among North Saudi University students. Cranio. 2016; 34(3): 176-181.

PubMed Abstract | Publisher Full Text 


\section{Open Peer Review}

\section{Current Peer Review Status: ?}

\section{Version 1}

Reviewer Report 07 April 2022

https://doi.org/10.5256/f1000research.80143.r126222

(C) 2022 Farag A. This is an open access peer review report distributed under the terms of the Creative Commons Attribution License, which permits unrestricted use, distribution, and reproduction in any medium, provided the original work is properly cited.

\section{Arwa Farag}

Division of Oral Medicine, Department of Diagnostic Sciences, Tufts School of Dental Medicine, Boston, MD, USA

Dear author,

Thank you for conducting this investigation. The study aimed to estimate the prevalence of TMDs among dental student and characterize the most common TMD diagnoses along with associated symptoms/conditions. The methodology followed was optimal, starting from screening to comprehensive clinical assessment and self-reported questionnaires. Recruitment and inclusion of the study participants were done using the gold standard diagnostic criteria (RDC-TMD). All the utilized tools of assessment were reliable and previously validated for TMD population.

Below, I'm including minor points/comments, that I hope will further optimize this well-puttogether manuscript.

Methodology:

In the exclusion criteria, author should specify that health history was obtained and those with underlying rheumatoid conditions, generalized pain symptoms, connective tissue disorders were excluded from the study.

\section{Discussion:}

It would great if the author can provide some statistics/citations for prevalence of TMD (disc displacement/myalgia) along with stress and anxiety in the general population and compare them to this special population (dental students). This will provide insight, and clearly highlight, the increased prevalence of these conditions among dental students.

Thank you once again for allowing me the opportunity to review this work.

Is the work clearly and accurately presented and does it cite the current literature? 
Yes

Is the study design appropriate and is the work technically sound?

Yes

Are sufficient details of methods and analysis provided to allow replication by others? Yes

If applicable, is the statistical analysis and its interpretation appropriate?

I cannot comment. A qualified statistician is required.

Are all the source data underlying the results available to ensure full reproducibility? Yes

Are the conclusions drawn adequately supported by the results?

Yes

Competing Interests: No competing interests were disclosed.

Reviewer Expertise: OFP and OM

I confirm that I have read this submission and believe that I have an appropriate level of expertise to confirm that it is of an acceptable scientific standard, however I have significant reservations, as outlined above.

Author Response 21 Apr 2022

Lujain Homeida, Umm al-Qura University, College of Dentistry, Saudi Arabia

Response to TMD reviewer comments

Thank you for the comments and the review, below are our responses

1 - in the exclusion criteria, author should specify that health history was obtained and those with underlying rheumatoid conditions, generalized pain symptoms, connective tissue disorders were excluded from the study.

Thank you for the comment, the material and method section was amended as follows: under TMJ clinical examination and diagnosis the following sentence was added:

"Detailed medical history was obtained and subjects with underlying rheumatoid conditions, generalized pain symptoms, connective tissue disorders were excluded from the study".

2- It would great if the author can provide some statistics/citations for prevalence of TMD (disc displacement/myalgia) along with stress and anxiety in the general population and compare them to this special population (dental students). This will provide insight, and clearly highlight, the increased prevalence of these conditions 


\section{among dental students.}

Thank you for this point. Most of the literature on TMD addressed specific population (patients, medical or dental students, or university students) very few literature addressed general population or included non TMD general population as a comparison group.

The following paragraph was added to the discussion.

'In comparison to the general population, TMD prevalence ranges between 5 - $35 \%$ (Schiffman, Ohrbach et al. 2014, Nadershah 2019). However, none of those studies reported on the association of TMD with stress, anxiety or phycological factors in general population. In general, anxiety disordered have been reported in $35 \%$ of chronic pain patients compared to only $18 \%$ of the general population (Poleshuck, Bair et al. 2009). in addition, Reissmann et al. compared patients diagnosed with TMD and general population without TMD related pain and reported that Trait anxiety is significantly associated with diagnoses of TMD pain. One point increase in the State-Trait Anxiety Inventory score related to an increase of the odds for pain-related TMD by the factor 1.04 (Reissmann, John et al. 2014). A similar finding reported by kmeid et al. were TMDs was significantly associated with depression, anxiety, and stress among Lebanese population (Kmeid, Nacouzi et al. 2020)'

Competing Interests: N/A

The benefits of publishing with F1000Research:

- Your article is published within days, with no editorial bias

- You can publish traditional articles, null/negative results, case reports, data notes and more

- The peer review process is transparent and collaborative

- Your article is indexed in PubMed after passing peer review

- Dedicated customer support at every stage

For pre-submission enquiries, contact research@f1000.com 